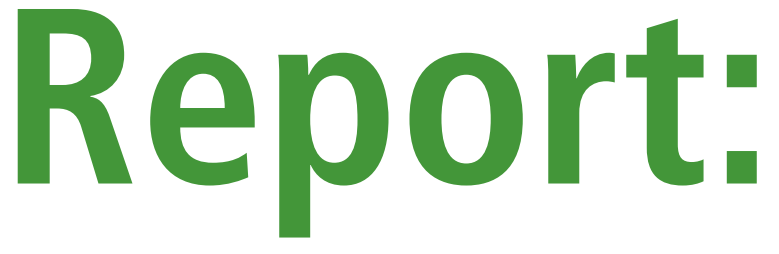

\title{
Patterns of fatherhood in England and Wales, 1964-2007
}

\section{Introduction}

This report presents new estimates of fatherhood in England and Wales between $1964^{1}$ and 2007 . The measures presented are the standardised ${ }^{2}$ mean age of father at childbirth, male Age-specific Fertility Rates (ASFR) and the male Total Fertility Rate (TFR). Fertility refers here to reproductive behaviour (the number of children born) rather than the actual ability to reproduce. It is intended to publish estimates annually for 2008 onwards.

These estimates have been calculated using information from the birth registration system and mid-year population estimates. They supersede estimates published previously ${ }^{3}$ because they use revised calculation methods which are consistent across the entire period and incorporate the latest population estimates.

Calculating fertility measures for men is not as straightforward as for women, for two reasons:

- The age of the father is not collected at birth registration for births registered only by the mother

- Men often continue to have children at much older ages than women

The mid-section of this report highlights how these differences have been addressed to ensure that the male fertility measures produced are robust. The report then goes on to describe how the male fertility measures are actually calculated. To start with, however, the new estimates of fatherhood are analysed to reveal how trends in fatherhood have changed since 1964. These trends are also compared with those observed for women.

\section{Patterns of fatherhood in England and Wales, 1964-2007}

The standardised mean age of father at childbirth, male Age-specific Fertility Rates (ASFRs) and male Total Fertility Rate (TFR) for each year between 1964 and 2007 are reported in Table 1. The following sections address each measure in turn to consider how trends in fatherhood have changed over the last four decades and compare these against patterns seen among women.

\section{Standardised mean age at childbirth}

Since the mid 1970s both men and women in England and Wales have increasingly been having their children at older ages. The mean age of father at childbirth has increased steadily since 1974, from 29.4 to 32.4 years in 2007 (see Figure 1). Over the same period the mean age of mother has also risen, from 26.4 years in 1974 to 29.3 years in 2007 .

In contrast, between 1964 and the mid 1970s the mean age at childbirth for both mothers and fathers declined - this followed the early childbearing during the 1960s which contributed to the 1960s baby boom.

At childbirth, the mean age of father is typically around three years higher than the mean age of mother. This age difference has been evident since 1964 and reflects the fact that at marriage men are on average nearly three years older than women ${ }^{4}$, while for cohabiting couples the age difference is typically greater ${ }^{5}$.

\section{Age patterns of fertility}

In England and Wales, marked changes in age patterns of fatherhood have taken place over the last four decades (Figure 2). Between 1964 and 1977 male fertility rates generally decreased among all age groups except for those aged under 20. For men in their twenties this fertility decline continued to 2001. Fertility levels of men aged under 20 have fluctuated somewhat between 1964 and 2007 but overall there has been a slight downward trend.

Following these fertility declines over the first part of the period, male fertility rates have increased. For men in their fifties and sixties, this increase was interrupted by a slight decline in fertility during the 1990s. Since 2001 however, male fertility levels have generally increased for all age groups except for men under 20. The greatest increases occurred for men in their late thirties, forties and early fifties, where fertility rates rose by over 25 per cent. In 2007, male fertility levels exceed those observed in 1964 at ages $35-39$ and $40-44$.

Over the same period, similar age patterns of fertility have been observed among women ${ }^{6}$, with declining fertility followed by increasing fertility at all ages except those aged under 20. As for men, the initial decline in 


\begin{tabular}{|c|c|c|c|c|c|c|c|c|c|c|c|c|}
\hline \multirow[t]{2}{*}{ Year } & \multirow{2}{*}{$\begin{array}{l}\text { Standardised } \\
\text { mean age of } \\
\text { father }\end{array}$} & \multirow[t]{2}{*}{ Male TFR } & \multicolumn{10}{|c|}{ Male age-specific fertility rates (live births per 1,000 men in age group) } \\
\hline & & & Under 20 & $20-24$ & $25-29$ & $30-34$ & $35-39$ & $40-44$ & $45-49$ & $50-54$ & $55-59$ & 60 and over \\
\hline 1964 & 30.3 & 2.92 & 10.9 & 112.8 & 190.9 & 140.3 & 75.1 & 31.6 & 11.6 & 3.7 & 1.1 & 0.5 \\
\hline 1965 & 30.2 & 2.86 & 12.2 & 112.6 & 187.4 & 135.8 & 73.3 & 30.3 & 11.5 & 3.5 & 1.1 & 0.5 \\
\hline 1966 & 30.1 & 2.77 & 13.6 & 112.7 & 184.0 & 129.8 & 69.1 & 28.9 & 10.7 & 3.3 & 1.0 & 0.4 \\
\hline 1967 & 30.0 & 2.68 & 14.4 & 108.5 & 176.6 & 125.8 & 66.0 & 28.2 & 10.2 & 3.1 & 1.0 & 0.4 \\
\hline 1968 & 29.9 & 2.61 & 14.6 & 106.9 & 172.7 & 122.4 & 63.1 & 26.9 & 9.1 & 2.9 & 0.9 & 0.4 \\
\hline 1969 & 29.8 & 2.51 & 14.9 & 105.3 & 165.6 & 117.8 & 59.7 & 25.3 & 8.2 & 2.8 & 0.9 & 0.4 \\
\hline 1970 & 29.7 & 2.44 & 14.7 & 105.7 & 162.1 & 113.4 & 56.9 & 23.8 & 7.6 & 2.5 & 0.9 & 0.3 \\
\hline 1971 & 29.6 & 2.39 & 15.0 & 105.9 & 160.5 & 110.2 & 54.6 & 22.8 & 7.4 & 2.5 & 0.8 & 0.4 \\
\hline 1972 & 29.6 & 2.18 & 14.5 & 97.0 & 146.2 & 100.5 & 49.2 & 20.3 & 6.7 & 2.3 & 0.7 & 0.3 \\
\hline 1973 & 29.5 & 2.01 & 13.7 & 88.2 & 137.4 & 92.8 & 43.7 & 17.9 & 6.1 & 2.1 & 0.7 & 0.3 \\
\hline 1974 & 29.4 & 1.88 & 12.8 & 82.1 & 130.6 & 87.9 & 40.0 & 16.2 & 5.7 & 1.8 & 0.6 & 0.3 \\
\hline 1975 & 29.5 & 1.77 & 11.9 & 75.1 & 122.3 & 84.1 & 37.5 & 15.2 & 5.4 & 1.8 & 0.7 & 0.3 \\
\hline 1976 & 29.6 & 1.70 & 10.7 & 70.2 & 117.9 & 82.5 & 36.3 & 14.5 & 5.3 & 1.7 & 0.6 & 0.3 \\
\hline 1977 & 29.7 & 1.65 & 9.7 & 65.8 & 115.1 & 82.5 & 35.6 & 14.3 & 5.1 & 1.7 & 0.6 & 0.3 \\
\hline 1978 & 29.7 & 1.72 & 9.7 & 67.7 & 119.9 & 86.7 & 38.1 & 15.2 & 5.4 & 1.9 & 0.6 & 0.3 \\
\hline 1979 & 29.8 & 1.83 & 10.2 & 70.7 & 126.1 & 93.6 & 41.5 & 16.3 & 5.8 & 2.0 & 0.7 & 0.3 \\
\hline 1980 & 29.8 & 1.88 & 10.3 & 72.3 & 128.7 & 95.3 & 42.6 & 16.7 & 6.1 & 2.1 & 0.7 & 0.4 \\
\hline 1981 & 30.0 & 1.81 & 9.5 & 67.1 & 124.6 & 92.2 & 41.6 & 16.3 & 6.1 & 2.2 & 0.7 & 0.3 \\
\hline 1982 & 30.1 & 1.79 & 9.5 & 65.7 & 120.8 & 92.6 & 42.4 & 16.6 & 6.4 & 2.3 & 0.7 & 0.4 \\
\hline 1983 & 30.2 & 1.79 & 9.5 & 63.2 & 120.3 & 94.6 & 42.9 & 16.9 & 6.7 & 2.5 & 0.8 & 0.3 \\
\hline 1984 & 30.3 & 1.79 & 9.9 & 61.6 & 118.3 & 96.3 & 43.4 & 17.3 & 6.8 & 2.5 & 0.9 & 0.4 \\
\hline 1985 & 30.3 & 1.82 & 10.4 & 62.2 & 118.5 & 99.1 & 44.8 & 17.6 & 7.1 & 2.6 & 1.0 & 0.4 \\
\hline 1986 & 30.4 & 1.82 & 10.8 & 61.8 & 115.3 & 100.0 & 45.2 & 17.6 & 7.0 & 2.7 & 1.0 & 0.4 \\
\hline 1987 & 30.5 & 1.85 & 10.9 & 62.3 & 116.0 & 103.2 & 48.3 & 17.9 & 7.2 & 2.9 & 1.1 & 0.5 \\
\hline 1988 & 30.5 & 1.87 & 11.5 & 63.9 & 114.7 & 104.4 & 50.0 & 18.3 & 7.0 & 2.9 & 1.1 & 0.5 \\
\hline 1989 & 30.7 & 1.84 & 11.0 & 61.5 & 110.7 & 103.9 & 51.5 & 18.5 & 7.1 & 2.9 & 1.1 & 0.6 \\
\hline 1990 & 30.7 & 1.87 & 11.5 & 61.4 & 111.1 & 106.9 & 53.8 & 19.1 & 7.1 & 3.0 & 1.1 & 0.6 \\
\hline 1991 & 30.8 & 1.85 & 11.2 & 60.2 & 108.2 & 105.3 & 54.4 & 19.2 & 6.9 & 2.9 & 1.2 & 0.6 \\
\hline 1992 & 30.9 & 1.82 & 10.6 & 58.8 & 106.2 & 102.6 & 54.9 & 20.5 & 6.8 & 2.7 & 1.1 & 0.6 \\
\hline 1993 & 31.1 & 1.77 & 9.9 & 54.6 & 101.1 & 103.2 & 56.2 & 20.5 & 6.9 & 2.7 & 1.1 & 0.7 \\
\hline 1994 & 31.3 & 1.75 & 8.8 & 51.7 & 98.3 & 103.3 & 57.8 & 21.2 & 6.9 & 2.6 & 1.1 & 0.6 \\
\hline 1995 & 31.3 & 1.71 & 8.8 & 49.6 & 94.1 & 100.7 & 57.5 & 21.6 & 6.9 & 2.5 & 1.1 & 0.6 \\
\hline 1996 & 31.4 & 1.72 & 9.1 & 49.9 & 93.0 & 100.5 & 58.6 & 22.4 & 7.0 & 2.6 & 1.1 & 0.6 \\
\hline 1997 & 31.5 & 1.71 & 9.4 & 49.0 & 90.7 & 99.2 & 60.0 & 23.2 & 7.3 & 2.6 & 1.0 & 0.5 \\
\hline 1998 & 31.5 & 1.70 & 10.0 & 48.0 & 88.6 & 98.9 & 60.5 & 23.6 & 7.6 & 2.5 & 1.0 & 0.6 \\
\hline 1999 & 31.6 & 1.67 & 10.4 & 46.6 & 85.2 & 96.7 & 60.3 & 23.9 & 7.6 & 2.5 & 1.0 & 0.5 \\
\hline 2000 & 31.7 & 1.62 & 9.9 & 44.6 & 79.9 & 94.6 & 60.3 & 24.1 & 7.8 & 2.5 & 0.9 & 0.5 \\
\hline 2001 & 31.8 & 1.60 & 9.5 & 43.8 & 77.0 & 93.6 & 59.6 & 24.6 & 7.9 & 2.5 & 0.9 & 0.6 \\
\hline 2002 & 31.9 & 1.61 & 9.1 & 44.0 & 75.8 & 94.7 & 60.8 & 25.3 & 8.1 & 2.5 & 0.9 & 0.6 \\
\hline 2003 & 32.0 & 1.68 & 9.2 & 45.5 & 78.0 & 99.3 & 64.3 & 27.4 & 8.9 & 2.8 & 0.9 & 0.6 \\
\hline 2004 & 32.1 & 1.74 & 9.4 & 46.0 & 79.8 & 102.6 & 67.2 & 28.6 & 9.4 & 2.8 & 1.0 & 0.6 \\
\hline 2005 & 32.2 & 1.75 & 9.5 & 44.9 & 79.4 & 103.3 & 68.5 & 29.4 & 9.8 & 3.0 & 1.0 & 0.6 \\
\hline 2006 & 32.2 & 1.81 & 9.5 & 45.4 & 81.9 & 107.2 & 72.6 & 30.4 & 10.3 & 3.2 & 1.0 & 0.6 \\
\hline 2007 & 32.4 & 1.87 & 9.5 & 45.3 & 83.7 & 111.1 & 76.0 & 31.7 & 10.8 & 3.3 & 1.0 & 0.5 \\
\hline
\end{tabular}

fertility was more prolonged for women in their twenties compared with older ages.

In 1964 men aged between 25 and 29 experienced the highest fertility levels. Since 1993, however, fertility has been highest among males aged between 30 and $34-$ a consequence of the opposing fertility trends among men aged 25-29 and 30-34 between 1978 and 2001. A similar change occurred among women, but the crossover from highest fertility at ages 25-29 to 30-34 occurred in 2004- 11 years after the crossover occurred among men.

\section{Total Fertility Rate}

Since 1964, the male Total Fertility Rate (TFR) has been very similar to the female TFR (Figure 3). During the period 1964 to 1977, both the male and female TFRs decreased rapidly, falling from just over 2.9 children per man/woman to around 1.65. From 1978 the TFRs began to rise, but this was short-lived and during the 1980s the TFRs remained relatively stable, fluctuating between 1.75 and 1.87 . Throughout the 1990s fertility fell steadily, reaching a record low in 2001 of 1.60 for males and 1.63 for females. Since 2001 the TFR for both males and 


\section{Figure 1}

Standardised mean age of father and mother, England and Wales, 1964-2007

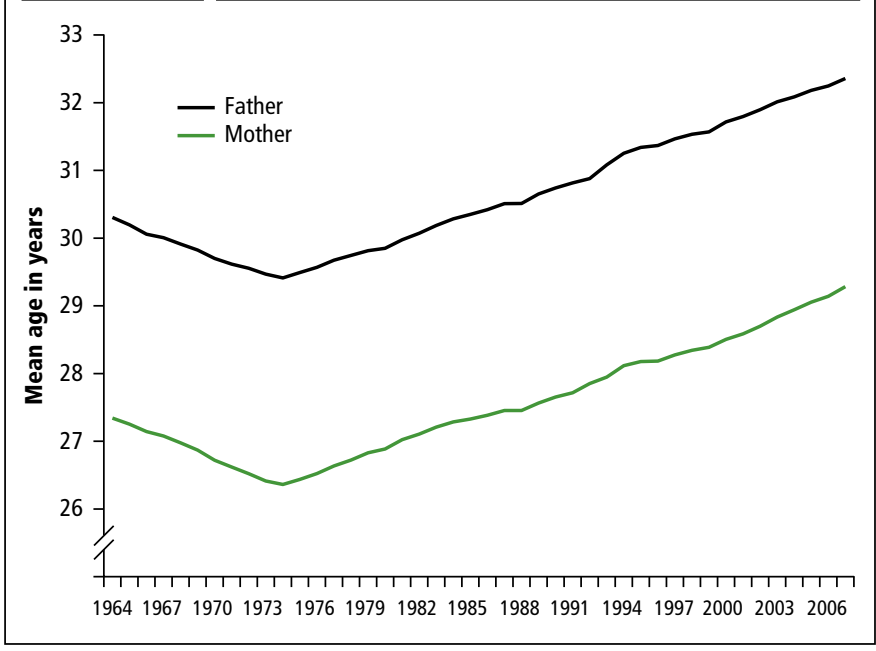

\section{Figure 2a}

Male age-specific fertility rates, England and Wales, 1964-2007

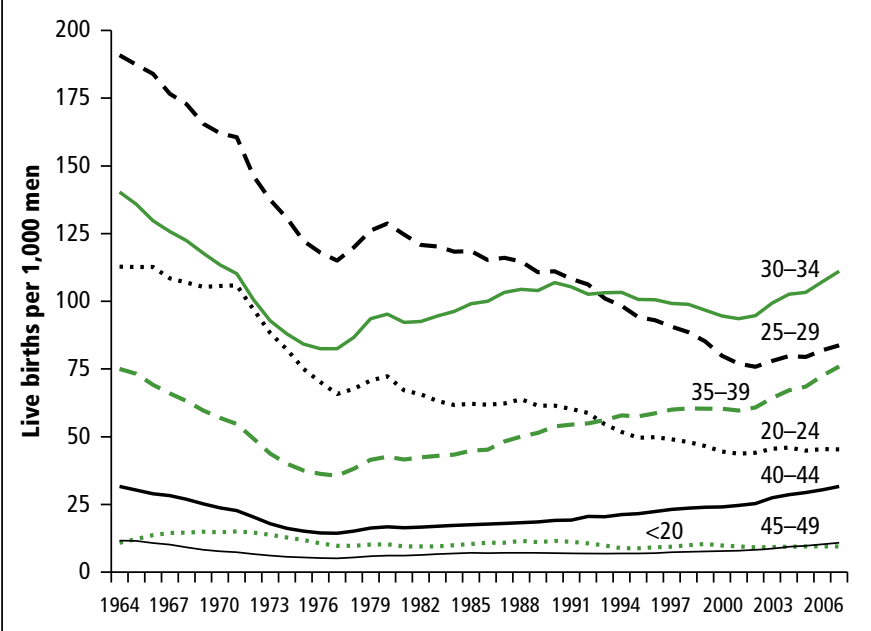

\section{Figure 2b}

Male age-specific fertility rates for age 45 and above, England and Wales, 1964-2007

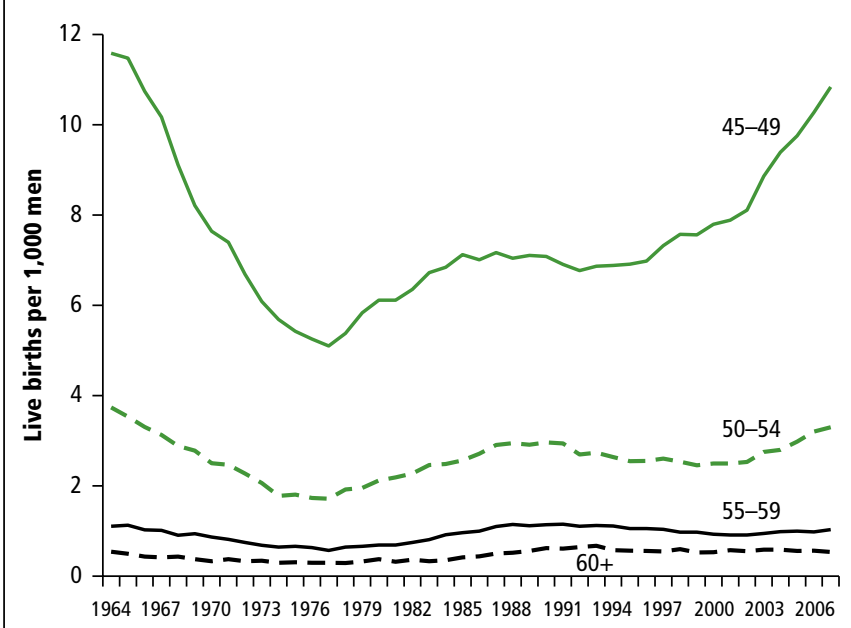

\section{Figure 3}

Total Fertility Rate for males and females, England and Wales, 1964-2007

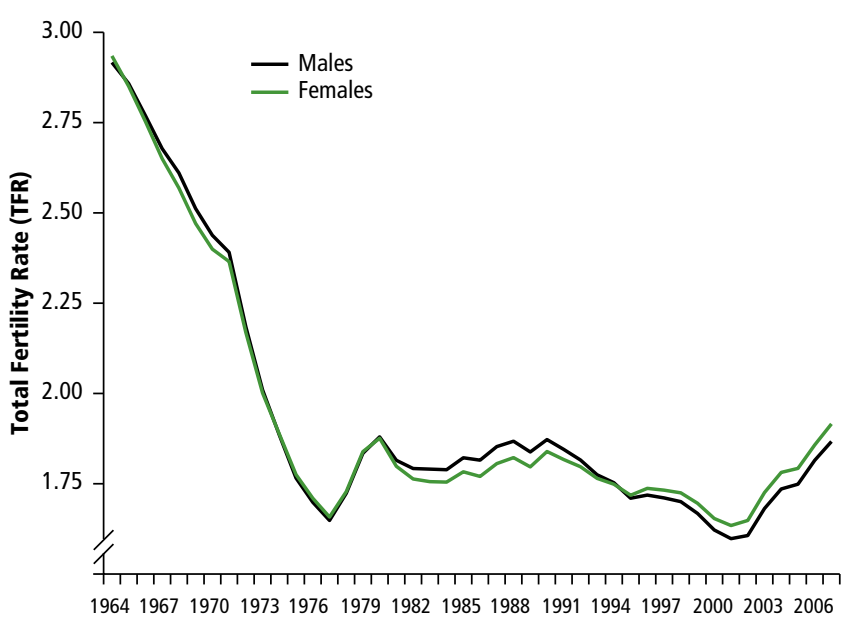

females has risen gradually. In 2007 the male TFR (1.87) was slightly lower than the female TFR (1.92).

Intuitively, overall male and female fertility might be expected to be the same, but in reality, slight differences between the male and female TFRs do occur. During the periods 1965 to 1973, and 1981 to 1993, the TFR was higher for males, while since 1995 the female TFR has been higher. These differences could result from:

- Differences in the age at childbearing for males and females and changes in this over time. For instance in 2007, the number of births to women exceeded those to men at each single year of age below 32. At ages 32 and above there were a greater number of births to men than women

- Differences in the numbers of males and females in the resident population at reproductive ages. For example, in 2007, women in England and Wales outnumbered men at all single years of age below 34. In contrast, men outnumbered women for all ages 34 and above

\section{Estimating age of father for sole registered births}

The age of the father is collected at birth registration for all births within marriage and for births outside marriage which are jointly registered. To derive male fertility measures for all fathers, it has been necessary to estimate the age of the father for births outside marriage which are registered solely by the mother. In England and Wales, 6.6 per cent of births in 2007 were sole registered. The proportion of sole registrations does vary by age with the highest proportion of sole registrations occurring among those aged under 20 (over one-fifth of such births were sole registered in 2007).

To estimate age of father for sole registered births, it has been assumed that for each age of mother, a suitable donor distribution for father's age can be provided by births outside marriage which are jointly registered. A separate 'father's age distribution' is therefore calculated for each age of mother (single years) for all births outside marriage which are jointly registered. These distributions are then applied to the number of sole registered births by each age of mother. Applying a separate 'father's age distribution' for each age of mother takes into account any differences between the ages of mothers for sole and jointly registered births. This method enables age of father for sole registered births to be estimated consistently over time. Previously published estimates ${ }^{7}$ used births outside marriage which were jointly registered by parents 
living at different addresses as a donor distribution for sole registered births between 1986 and 2004. Prior to 1986, no distinction was possible between joint registrations where parents lived at the same address and joint registrations where parents lived at different addresses. Consequently the father's age for sole registered births prior to 1986 was estimated using all births outside marriage which were jointly registered.

Government proposals to encourage joint birth registration ${ }^{8}$ are due to be implemented in the near future. As a result, father's age is likely to need estimating on an even smaller number of births in the future.

\section{Reproductive age for men}

For the purpose of demographic estimates in England and Wales, both men and women are considered to enter their reproductive years when they reach age 15 . The number of births to males and females aged below 15 is relatively low. In 2007, there were 928 live births recorded to women aged 15 but only 187 live births at age $14^{9}$. Similar results are observed among males but at lower levels, with 179 live births at age 15 in 2007, but only 32 live births at age $14^{10}$. When calculating fertility rates by single year of age or five-year age group, the lowest age groups used are actually 'under 16' and 'under 20 ' respectively and therefore include births to women below age 15 . The reproductive age range is however used for the population denominators.

Women are considered to have completed their childbearing years once they reach 45 years of age. Until now, male fertility measures have not been routinely calculated and there is no 'standard' age at which men are considered to have completed their reproductive years. Figures show that men continue to have children at much older ages than women. It would therefore be inappropriate to use the same top age limit for both sexes.

Several top reproductive age limits were considered for men. The most appropriate top age limit was selected after analysing the following for each proposed top age limit:

- The number of births

- The level of the male age-specific fertility rates at that age

- The impact on the mean age of father at childbirth

- The impact on the male TFR

This analysis highlighted age 65 as the most suitable point at which men should be regarded as having completed their reproductive years. The final age at which men are still considered to be in their reproductive years is therefore 'age 64' when using single years of age or 'age 60 and over' when using five year age groups.

\section{Calculating the measures}

The fertility measures which have been calculated are described in more detail below.

\section{Age-specific Fertility Rate}

Age-specific Fertility Rates (ASFRs) enable a comparison of reproductive behaviour at different ages. They are typically calculated for women but such measures can be calculated for men.

Male ASFRs have been calculated by dividing the number of live births in a year to fathers in each age group by the number of men in the midyear population of that age. Rates are expressed as the number of live births per 1,000 men in the age group. Male ASFRs will be published annually by five-year age groups in the reproductive age range, from under 20 up to 60 and over.
The Male ASFRs based on five-year age groups are given by:

$F_{a}^{m}=\frac{B_{a}^{m}}{P_{a}^{m}} \times 1,000$

where:

$F_{a}^{m}=$ age-specific fertility rate for males in age group $a$,

$B_{a}^{m}=$ live births to women in age group $a$,

$P_{a}^{m}=$ male population in age group $a$,

$a=$ age group: Under $20,20-24, \ldots, 55-59,60$ and over

For the groups 'under 20' and ' 60 and over', the male populations used are men aged $15-19$ and men aged 60-64 respectively.

Male ASFRs by single year of age have also been calculated to enable the male TFR for England and Wales to be derived.

\section{Total Fertility Rate}

The Total Fertility Rate (TFR) is typically calculated for women. It is however also possible to calculate a male TFR which represents the average number of children that a group of men would each father if they experienced the male ASFRs for a particular year throughout their reproductive years. The TFR provides a measure of the current level of fertility. It can be affected by changes in the timing of childbearing so it may not reflect the average number of children that men will have by the end of their reproductive years. For example if men delay having children to older ages, the TFR may underestimate average family size. In contrast, if men begin to have children at younger ages than previous generations, the TFR will overestimate average family size.

The Male TFR is derived by summing single-year ASFRs over all ages within the childbearing lifespan:

$\operatorname{TFR}^{m}=\sum_{a=\operatorname{under} 16}^{a=64 \text { and over }} F_{a}^{m}$

where:

$F_{a}^{m}=\frac{B_{a}^{m}}{P_{a}^{m}}$,

and

$B_{a}^{m}=$ live births to men in age group $a$,

$P_{a}^{m}=$ male population in age group $a$,

$a=$ ages: Under $16,16,17, \ldots, 62,63,64$ and over

For the groups 'under 16' and ' 64 and over', the male populations used are men aged 15 and men aged 64 respectively.

\section{Standardised mean age at childbirth}

The standardised mean age at childbirth is published annually for mothers ${ }^{11}$. Standardising eliminates the effect of year-to-year changes in the age structure of the population and enables trends to be analysed. The standardised mean age of father has been calculated by multiplying the single-year ASFRs per 1,000 men by the age of the father in completed years, summing across all reproductive ages and then dividing by the sum of the single-year ASFRs across all reproductive ages. Since the ages used are discrete variables representing completed years and mean age is a continuous variable, it is necessary to add a further 0.5 years to derive the mean age of father. This final adjustment reflects the fact that the actual age for all individuals who have completed $x$ years is actually $x+0.5$ years. 
The standardised mean age of father is given by:

$$
\bar{A}^{m}=\frac{\sum_{a=\text { under } 16}^{a=64 \text { and over }} a F^{m}}{\sum_{a=\text { under } 16}^{64 \text { and over }} F_{a}^{m}}+0.5
$$

where:

$$
F_{a}^{m}=\frac{B_{a}^{m}}{P_{a}^{m}} \times 1,000
$$

and

$B_{a}^{m}=$ live births to men in age group $a$,

$P_{a}^{m}=$ male population in age group $a$,

$a=$ ages: Under $16,16,17, \ldots, 62,63,64$ and over

\section{Notes and references}

1 Birth registration data are not available electronically before 1964 .
2 Standardised for the age distribution of the population. Standardised measures are more appropriate for use when analysing trends.

3 Chamberlain J and Gill B (2005) Focus on People and Migration, Chapter 5: Fertility and mortality. Available at: www.statistics.gov. uk/downloads/theme_compendia/fom2005/Migration_Chap01-05.zip

4 Marriage, divorce and adoption statistics, Series FM2, Tables 3.16 and 3.17. Available at: www.statistics.gov.uk/StatBase/Product.asp?vlnk=581

5 Hancock R, Stuchbury R and Tomassini C (2003) 'Changes in the distribution of marital age differences in England and Wales, 1963 to 1988'. Population Trends 114, 19-25.

6 See Figure 2, 'Annual Update: Births in England and Wales, 2007'. Population Trends 134, 85-89. Available at:

www.statistics.gov.uk/StatBase/Product.asp?vlnk=6303

7 See reference 4 - Chamberlain J and Gill B (2005).

8 http://publications.desf.gov.uk/default.aspx?PageFunction=productde tails\&PageMode $=$ publications\&ProductId $=$ CM $\% 25207293$

9 Birth Statistics, Series FM1 Table 3.2. Available at: www.statistics.gov.uk/StatBase/Product.asp?vlnk=5768

10 Birth Statistics, Series FM1 Table 3.4. Available at: www.statistics.gov.uk/StatBase/Product.asp?vlnk=5768

11 Birth Statistics, Series FM1 Table 1.7b.Available at: www.statistics.gov.uk/StatBase/Product.asp?vlnk=5768 